\title{
Prototype Buka Tutup Pintu Berbasis Arduino Uno Dan Android
}

\author{
Arnes Sembiring ${ }^{1},{ }^{2}$ M.Rizky Pahlepy Lubis \\ Universitas Harapan Medan, Fakultas Teknik dan Komputer, Program Studi Teknik Informatika,
} Indonesia ${ }^{1,2}$

Email : riezkypahlepy1@gmail.com ${ }^{1}$

* Corresponding author

\begin{abstract}
Abstrak -
Pada prinsipnya tujuan penciptaan robot adalah untuk mempermudah kegiatan manusia bahkan menggantikan peran manusia dalam suatu fungsi tertentu, salah satunya yaitu dalam hal membuka dan menutup pintu rumah. Salah satu usaha untuk memberikan kemudahan dan kenyamanan bagi manusia tersebut adalah melalui pengembangan sistem otomasi pada rumah yang dapat membuka dan menutup pintu secara otomatis. Robot ini dirancang dengan sebuah perangkat pengaman pada pintu bebasis Arduino Uno. Alat ini berisi rangkaian mikrokontroler seperti Arduino uno, motor servo, bluetooth dan satu buah smartphone. Alat pengaman Bluetooth ini bekerja memakai arduino uno sebagai mikrokontroler. Motor servo sebangai alat untuk membuka dan menutup pintu tersebut dan sebagai media transmisi dan smartphone digunakan sebagai remender serta pengaplikasian password pada smartphone android. Alat ini bekerja berdasarkan motor servo yang digunakan untuk membuka dan menutup pintu dengan motor servo. Motor servo akan membuka dan menutup sesuai perintah yang diinginkan dengan cara menekan tombol button yang tersedia di Android.
\end{abstract}

Kata Kunci: Arduino Uno, Smartphone Android, Motor Servo, Bluetooth.

1. Latar Belakang

Otomasi yang dapat diterapkan di rumah adalah Manusia selalu berusaha untuk sistem yang dapat membuka dan menutup menciptakan sesuatu yang dapat meringankan pintu secara otomatis. Melalui pengembangan aktifitasnya dengan memanfaatkan teknologi. sistem ini diharapakan penghuni rumah dapat Karena dengan teknologi menjadiakan segala membuka pintu dari jarak tertentu tanpa harus sesuatu yang dilakukan menjadi lebih mudah. berinteraksi langsung dengan pintu tersebut. Hal ini yang mendorong perkembangan. Berdasarkan perkembangan teknologi, teknologi yang telah banyak menghasilkan alat terdapat suatu sistem mikrokontroler terbaru sebagai piranti untuk mempermudah kegiatan yaitu Arduino Uno yang dapat dimanfaatkan manusia bahkan menggantikan peran manusia untuk dikomunikasikan dengan smarthphone dalam suatu fungsi tertentu. Salah satu sistem android memalui Bluetooth, sehingga bisa digunakan untuk aplikasi membuka dan menutup pintu tanpa menggunakan cara yang konvensional, namun cukup diakses melalui smartphone Android saja.

Penelitian sebelumnya yang berhubungan dengan topik pembahasan mengenai prototype buka tutup pintu otomatis menggunakan bluetooth berbasis arduino uno dan android ini diataranya sebagai berikut :

Penelitian sebelumnya dengan topik pembahasan mengenai pintu otomatis. Secara 
garis besar alat ini dibangun sebagai salah satu usaha dalam kemajuan teknologi untuk memberikan kemudahan dan kenyamanan melalui pengembangan sistem otomasi pada rumah berupa pintu gerbang otomatis. Menggunakan Arduino Uno dapat mengendalikan alat sistem kerja dari kontrol pintu gerbang otomatis dengan bekerja sesuai urutan instruksi

pemograman. Selain itu, perintah pengontrol pintu gerbang diberikan melalui aplikasi pada smartphone Android yang dibuat menggunakan bahasa pemrograman Java. Dan sistem dapat menerima perintah untuk membuka pintu dari aplikasi smartphoneAndroid.[1]

Penelitian sebelumnya dengan topik pembahasan mengenai pintu otomatis. Secara garis besar alat ini dirancang untuk bekerja dengan baik menggunakan pengendali mikrokontroler arduino dalam pengoperasian data yang dikirim melalui module bluetooth. Selanjutnya jangkauan jarak dari modulebluetooth ini adalah 30 meter jika tampa adanya halangan atau hambatan. Jika didalam ruangan atau ada hambatan koneksi module bluetooth hanya terjangkau 24 meter saja. Dan dari sistem ini dapat bekerja untuk mengontrol suplai air dan pemberian makan ikan di peternakan ikan.

Jadi penulis merancang sebuah perangkat pengaman portabledengan menggunakan sensor jarak bebasis Arduino Uno. Alat ini berisi rangkain mikrokontroler seperti Arduino uno, sensor jarak, motor servo, bluetooth dan satu buah smartphone.

Alat pengaman portable bekerja memakai arduino uno sebagai mikrokontroller. Sensor jarak untuk mengetahui hewan memasuki kandang juga motor servo sebangai alat pengunci kandang tersebut dan Bluetooth sebagai media transmisi. Dan smartphone digunakan sebagai remender.[2]

\section{Analisis Dan Perancangan Sistem}

\subsection{Analisis Sistem}

Dalam merancang sebuah alat yang akan di bangun, terlebih dahulu di butuhkan analisis alat yang di perlukan agar menghasilkan suatu rancangan alat yang sesuai dengan yang di harapkan. Tujuan dari perancangan ini adalah membuat suatu keamanan pada pintu dengan password menggunakan motor servo. Alat tersebut adalah sebuah alat yang dapat menjadi sebuah keamanan pada pintu.

Keamanan pada pintu dengan password menggunakan motor servo merupakan alat yang dapat membantu manusia dalam kegiatan sehari-hari untuk menjaga barang-barang berharga secara efesien dengan menggunakan keamanan pada pintu dengan password menggunakan motor servo. Alat keamanan ini bekerja memakai arduino uno sebagai mikrokontroller alat tersebut, motor servo sebagai alat untuk membuka dan menutup pintu tersebut, lalu memanfaatkan passwordserta bluetooth sebagai media.

\subsection{Rangkaian Blok Diagram Alir Sistem}

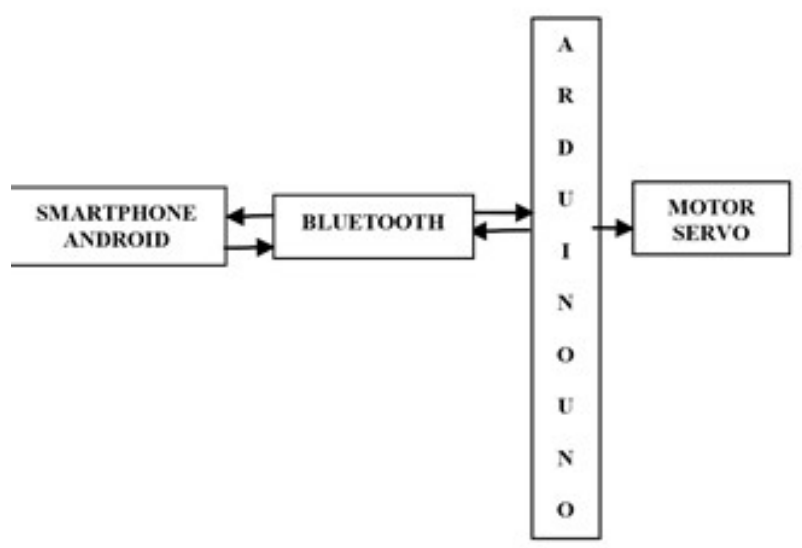

Gambar 1 Blok Diagram Sistem

Penjelasan dan fungsi dari masing masing blok pada blok diagram sistem di atas adalah sebagai berikut

Motor servo berfungsi untuk membuka dan mengunci pintu tersebut.

1. Bluetooth berfungsi sebagai media transmisi. 
2. Password pada android berfungsi sebagai Penjelasan tentang.

Diagram alir buka tutup pintu otomatis dari android pada gambar 3.3.1 di atas adalah sebagai berikut:

Kondisi awal mulai.

1. Masuk ke tampilan utama aplikasi Smartphone Android.

2. Klik dan masukkan username dan password.

3. Klik login.

4. Klik icon bluetooth ( icon yang ada pada aplikasi android) Pilih bluetooth (HC-05) dan bluetooth terhubung.

5. Klik open untuk membuka dan close untuk menutup pintu.

6. Input data dari android.

7. Menerima data dari android.

8. Pintu terbuka (serial1).

9. Pintu tertutup (seril0).

1) 2.4 Rangkaian BlokDiagram Alir Sistem Dari Bluetooth

7. Pintu tertutup.

\section{2) 2.5 Instalasi Rangkaian Bluetooth}

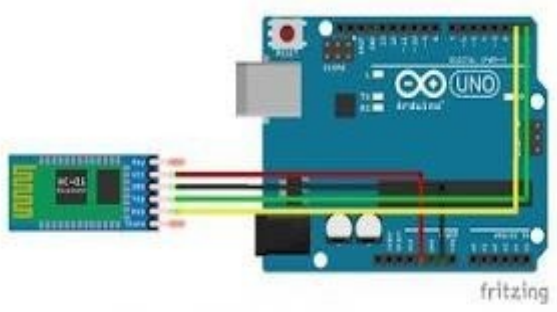

3) Gambar 4 Rangkaian Bluetooth

Bluetooth memiliki 4 kaki komponen diantaranya, kaki Vcc terhubung ke 5 Volt, kaki Ground terhubung ke Ground, kaki TXD

\section{St}

Bluetont

Bustanth ।

Menpri $\mathrm{Ti}^{\mathrm{P}}$ Pintu

Irimptala da Tertutu

Terbuk $\mathrm{k} \quad \mathrm{p}$

a

Gambar 3 Diagram Alir Keamanan Portable Dari Bluetooth Penjelasan tentang Diagram Alir keamanan portable dari bluetooth pada gambar 3.3.2 di atas adalah sebagai berikut :

1. Posisi awal mulai.

2. Bluetooth Aktif

3. Klik button open/close.

4. Menerima data serial"1" (jika ya).

5. Pintu terbuka.

6. Menerima data serial"0" (jika tidak). (Level) terhubung ke RX-0 dan kaki RXD terhubung ke TX-1 yang ada di arduino uno. [3]

a) 2.6 Instalasi Rangkaian Motor Servo

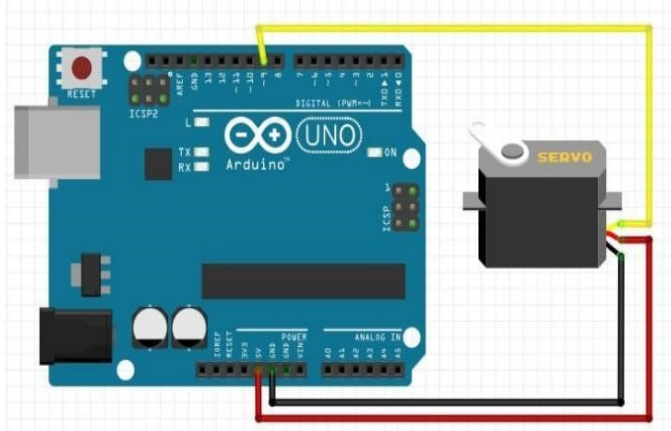

4) Gambar 5 Rangkian Motor Servo 
Motor servo memiliki 3 kaki komponen diantarany, kabel merah terhubung ke pin 5 Volt, kabel coklat/hitam terhubung ke Ground, Kabel kuning terhubung ke pin 9 Arduino.[4]

\section{b) 3. Implementasi Dan Pengujian Alat}

\subsection{Implementasi Sistem}

Implementasi sistem adalah sebuah tahapanuntuk menerapkan aplikasi yang telah dibuat sebelumnya, agar tercipta sebuah aplikasi yang diinginkan. Tahapan langkah-langkah implementasi.

\subsection{Cara Kerja Buka Tutup Pintu Otomatis} Sebelum masuk pada tahap implementasi dan pengujian alat, penulis akan menjelaskan terlebih dahulu cara kerja alat ini, yaitu sebagai berikut :

1. Buka Aplikasi keyprog yang telah terpasang di android.

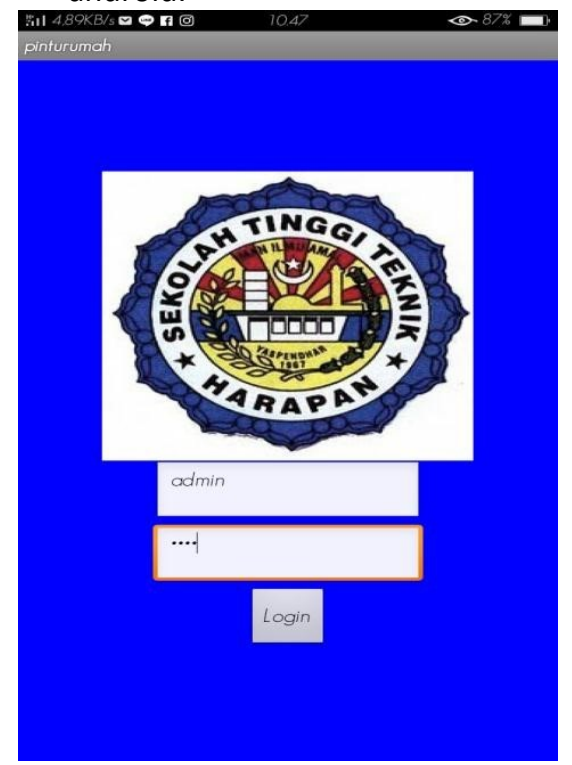

Gambar 6 Tampilan Utama Aplikasi Sistem Pada Smartphone Android

2. Setelah berhasil membuka aplikasi, hal selanjutnya yang perlu dilakukan adalah memilih perangkat Bluetooth arduino.

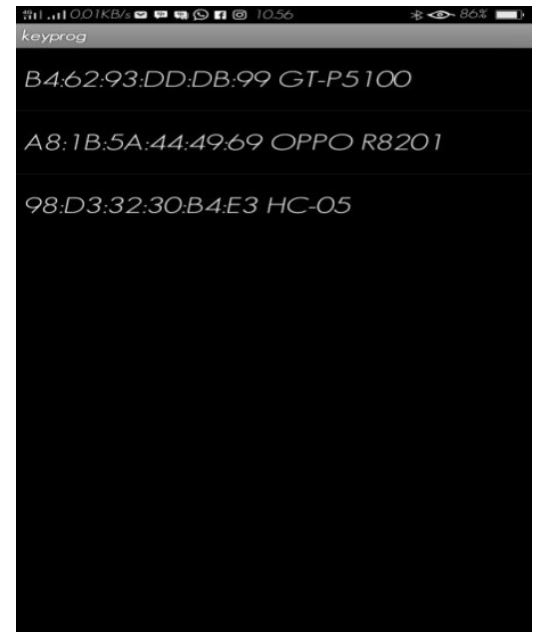

Gambar 7 Tampilan Aplikasi Saat Memilih Perangkat Bluetooth

3. Setelah memilih perangkat Bluetooth arduino maka hal selanjutnya yang harus dilakukan adalah klik open untuk membuka pintu, close untuk menutup pintu, dan logout untuk keluar dari aplikasi.
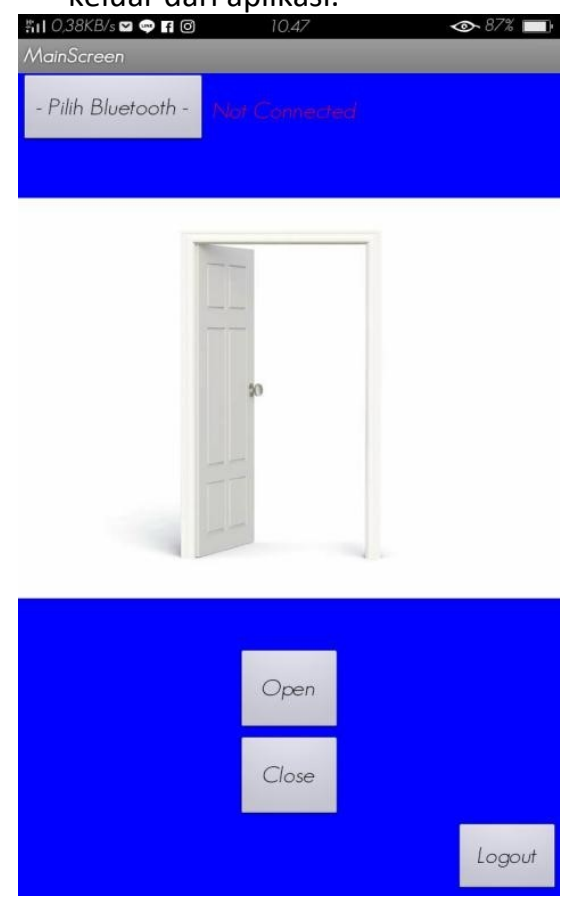

Gambar 8 Tampilan Aplikasi Memilih button open, close, dan logout
Pengujian
ini
di

lakukan untuk mengetahui apakah semua alat sudah berjalan dengan baik atau belum sesuai 
dengan yang di rencanakan. Untuk mengetahui apakah semuanya telah berjalan dengan baik maka harus kita harus menghidupkan powerbank terlebih dahulu untuk mengaktifkan arduino.

Tabel 1 Tabel Pengujian Rangkaian

\begin{tabular}{|l|l|l|l|l|}
\hline N o & $\begin{array}{l}\text { Keadaan } \\
\text { Arduino }\end{array}$ & $\begin{array}{l}\text { Keadaan } \\
\text { Bluetooth }\end{array}$ & Button & $\begin{array}{l}\text { Keteran } \\
\text { gan }\end{array}$ \\
\hline 1 & Aktif & $\begin{array}{l}\text { Tersambu } \\
\text { ng }\end{array}$ & Open & $\begin{array}{l}\text { Pintu } \\
\text { terbuka }\end{array}$ \\
\hline 2 & Aktif & $\begin{array}{l}\text { Tersambu } \\
\text { ng }\end{array}$ & Close & $\begin{array}{l}\text { Pintu } \\
\text { tertutup }\end{array}$ \\
\hline 3 & Aktif & $\begin{array}{l}\text { Tidak } \\
\text { tersambun g }\end{array}$ & Logout & $\begin{array}{l}\text { Kembali } \\
\text { ketampil } \\
\text { an awal }\end{array}$ \\
\hline 4 & Aktif & $\begin{array}{l}\text { Tidak } \\
\text { tersambun g }\end{array}$ & Error & $\begin{array}{l}\text { Non- } \\
\text { Aktif }\end{array}$ \\
\hline 5 & $\begin{array}{l}\text { Non- } \\
\text { Aktif }\end{array}$ & $\begin{array}{l}\text { Tidak } \\
\text { tersambun g }\end{array}$ & Error & $\begin{array}{l}\text { Non- } \\
\text { Aktif }\end{array}$ \\
\hline & & & & \\
\hline
\end{tabular}

Keseluruhan Arduino Uno dengan Android.

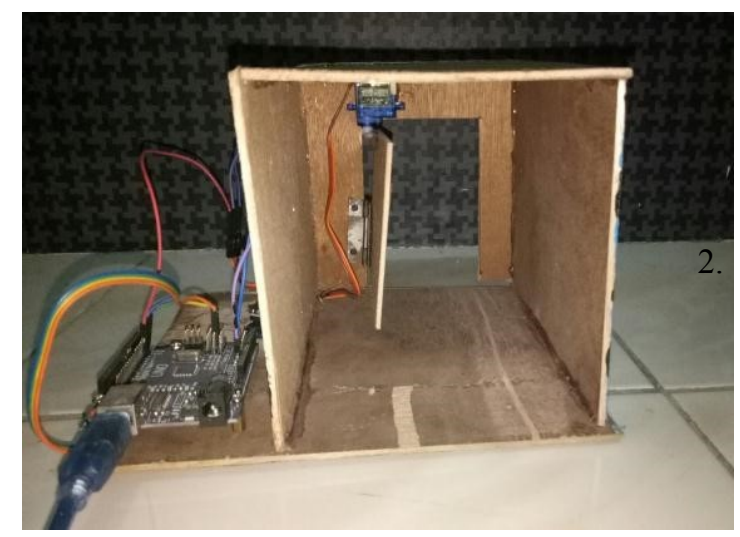

5) Gambar 9 Mengaktifkan prototype pintu terbuka otomatis

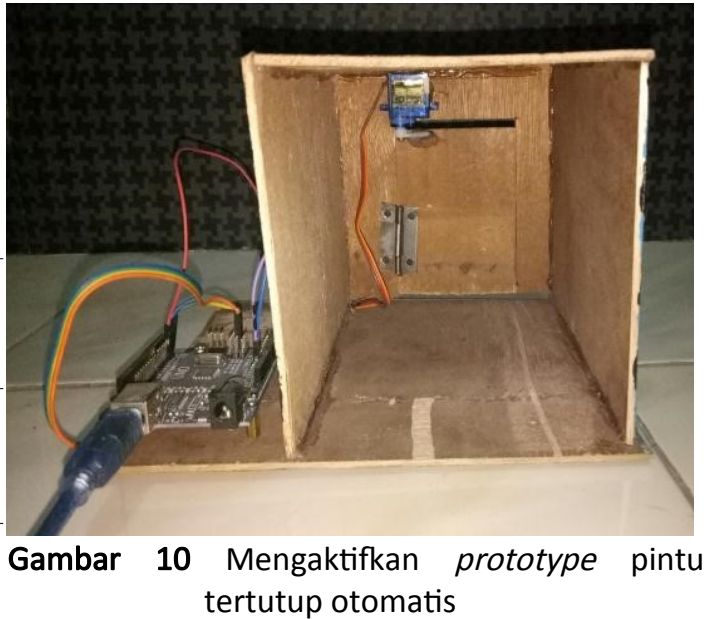

c)

4. Kesimpulan Dan Saran

\subsection{KESIMPULAN}

Setelah selesai melakukan tahap perancangan dan pembuatan sistem yang kemudian dilanjutkan dengan tahap implementasi dan pengujian alat maka dapat diambil kesimpulan bahwa untuk merancang dan membangun sebuah prototype buka tutup pintu otomatis menggunakan aplikasi android yaitu : Dengan menggunakan motorservo yang direkatkan ke pintu agar orang yang ingin membuka pintu tersebut tidak bisa membuka pintu secara langsung harus melalui aplikasi android.

Dengan menggunakan bluetooth maka user dapat tetap terhubung dengan perangkat tanpa menggunakan kabel dengan jarak maksimal 15 meter dalam kondisi ruang terbuka dan \pm 10 meter dalam kondisi ruang tertutup.

Dengan menggunakan smartphone android yang hampir dimiliki oleh setiap orang ini sebagai salah satu media yang dapat mengontrol untuk membuka dan menutup pintu tersebut secara otomatis dan juga akan mempermudah user karena tidak perlu membuka pintu secara langsung.

\subsection{SARAN}


Dari hasil tugas akhir yang penulis kerjakan ini masih terdapat beberapa kekurangan dan dimungkinkan untuk pengembangan lebih lanjut. Oleh karenanya penulis merasa perlu untuk memberi saran-saran sebagai berikut :

1. Perlu ditambahkannya Buzzer agar lebih aman bagi pemilik rumah dan jika sewaktuwaktu ada orang yang ingin mencuri barang didalam rumah tersebut.

2. Diharapkan untuk pengembangan selanjutnya tidak lagi menggunakan bluetooth, melainkan menggunakan jaringan internet. Karena komunikasi dengan jaringan internet akan jauh lebih luas dan cepat dibandingkan bluetooth yang memiliki batasan jarak yang dekat.

3. Perlu ditambahkannya switch untuk menghidup/matikan powerbank agar tidak terjadinya pemakaian daya yang tidak diperlukan saat alat sedang tidak digunakan.

\section{Daftar Pustaka}

[1] Prakasa, 2017, Prototype Sistem Kunci Pintu Berbasis Qrcode Dan Arduino, 15, Surakarta

[2] Anip Febtriko. 2017, Sistem Kontrol Peternakan Ikan Dengan Menggunakan Mikrokontroler Berbasis Android, Teknik Informatika Fakultas Teknik Universitas Abdurrab.

[3] Dearyoti, 2016, Apaltu Bluetooth Pengertian Bluetooth dan Fungsinya, http://www.dearyoti.com/apaitubluetooth-pengertianbluetoothdanfungsinya/,TanggalAkses 04/07/2017

[4] Sora,2015, Pengertian Bluetooth Fungsi dan Cara Kerjanya, http://www.pengertianku.net/2015/03/p enger tian-bluetooth-fungsi-dancarakerjanya.html, Tanggal Akses 27/01/2017 